\title{
INFLUENCE THE STRUCTURE OF THE ROAD SURFACE ON THE MEASUREMENT OF DISTANCE AND SPEED USING OPTICAL HEAD
}

\author{
Slawomir Taubert \\ Motor Transport Institute \\ Environmental Protection Centre \\ Jagiellonska Street 80, 03-301 Warszawa, Poland \\ tel.: +48224385 517, fax: +48224385401 \\ e-mail: slawomir.taubert@its.waw.pl \\ Andrzej Wierzejski \\ Motor Transport Institute \\ Vehicle Type-Approval \& Testing Department \\ Jagiellońska Street 80, 03-301 Warszawa, Poland \\ tel.: +48 224385 514, fax: +48224385401 \\ e-mail: andrzej.wierzejski@its.waw.pl
}

\begin{abstract}
The optical head is a linear vehicle speed sensor. Its action is based on image analysis of the moving road surface. A special algorithm converts it on the speed signal. Because the image of a road is analyzed, therefore the change in structure of the road surface causes change of the signal from the optical head. Therefore, for each type of surface, it is necessary to calibrate the optical head. Calibration consists of measuring, using an optical head, the length of the measurement distance, which was previously precisely measured with another reference device. Based on these two values the calibration factor is calculated, and entered afterwards in the optical head control software.

This optical head is used in several the road tests, and its speed measurement function is used in the measurement of vehicle acceleration, braking distance, the total vehicle road load. This device, connected to the recorder, is also used in research on motion parameters of vehicle under real driving conditions. During these tests may occur the change of the road surface, therefore it is particularly important to know the influence of road surface structure on the signal from the optical head.

This paper presents the results of optical head tests on the road with different structure and surface quality.
\end{abstract}

Keywords: Road tests, measurement of distance and speed

\section{Introduction}

Distance and speed measurements are basic measurements performed for vehicles in on road tests in real traffic conditions. Registration of the vehicle speed deviation in time domain enable to create test cycles representing real traffic condition. Measurement of speed is also used to reproduce the defined cycle on the road for example fuel consumption measurements in SORT tests. Moreover speed and distance measurements are used in measurement of the vehicle rolling resistance on the road, vehicle dynamic measurements or braking performance. In all of these applications it is necessary to measure speed and distance with sufficient accuracy.

The basic equipment used in above mentioned measurements are: Peiseler wheel, systems based on GPS signal, optical head or devices converting signals from the engine ECU or ABS sensors. In this paper the speed and distance measurements with optical head analyzing the changes of the images of the moving road under the optical sensor is discussed. 


\section{Test description}

The road surface design and its condition influencing the distance measurements was analyzed (and indirectly influencing speed measurements also) measured with optical head. Two road surfaces extremely different were selected for the tests: good quality asphalt with a small texture depth and poor quality concrete surface with visible stones and rather high texture depth parameter and additionally road surface with paving BAUMA blocks widely used in residential areas (Fig. 1).

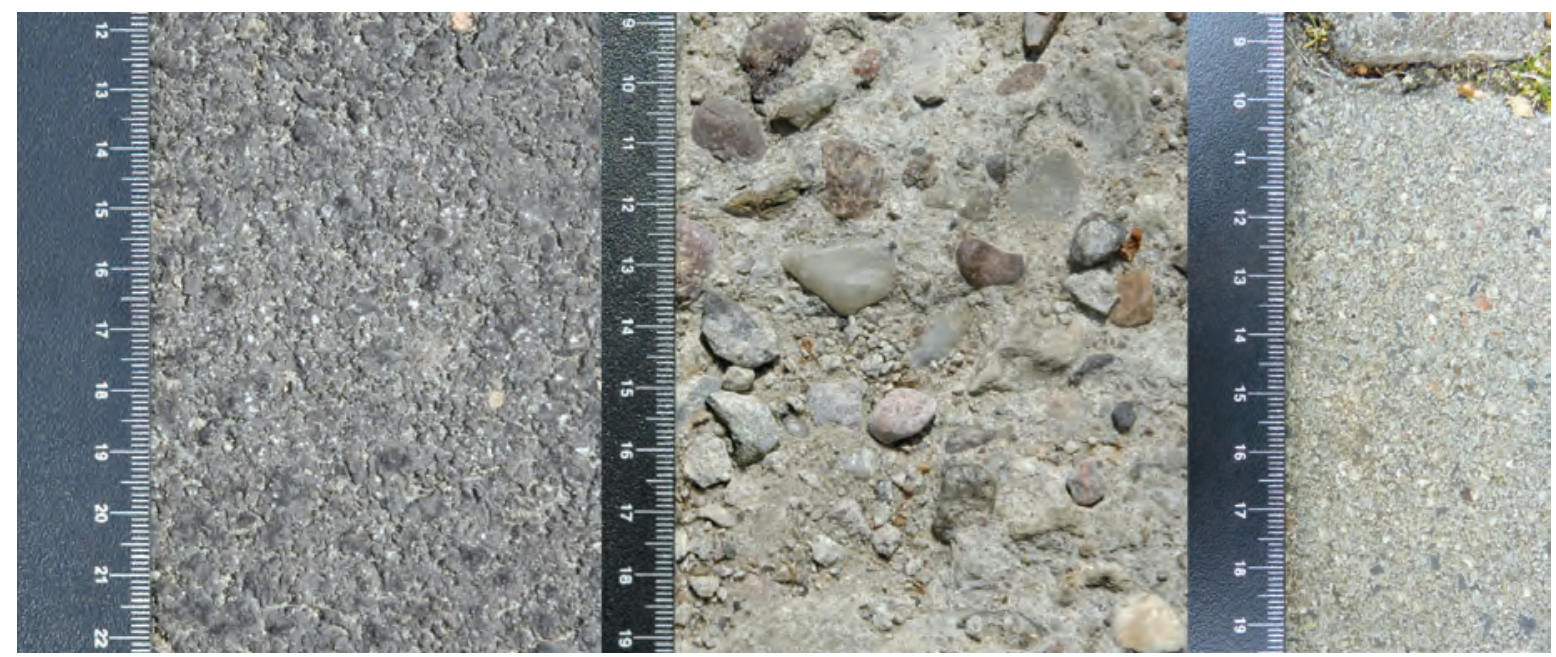

Fig. 1. Road surfaces (starting from left) good quality smooth asphalt, poor quality concrete road surface, pavement of Bauma bricks

On the measurement track two photo barriers with retroreflective elements were placed. The signals from the photo cells were reflected from the retroreflective barriers giving starting and stopping triggers. The distance between barriers was precisely measured with the laser distance meter (Fig. 2).

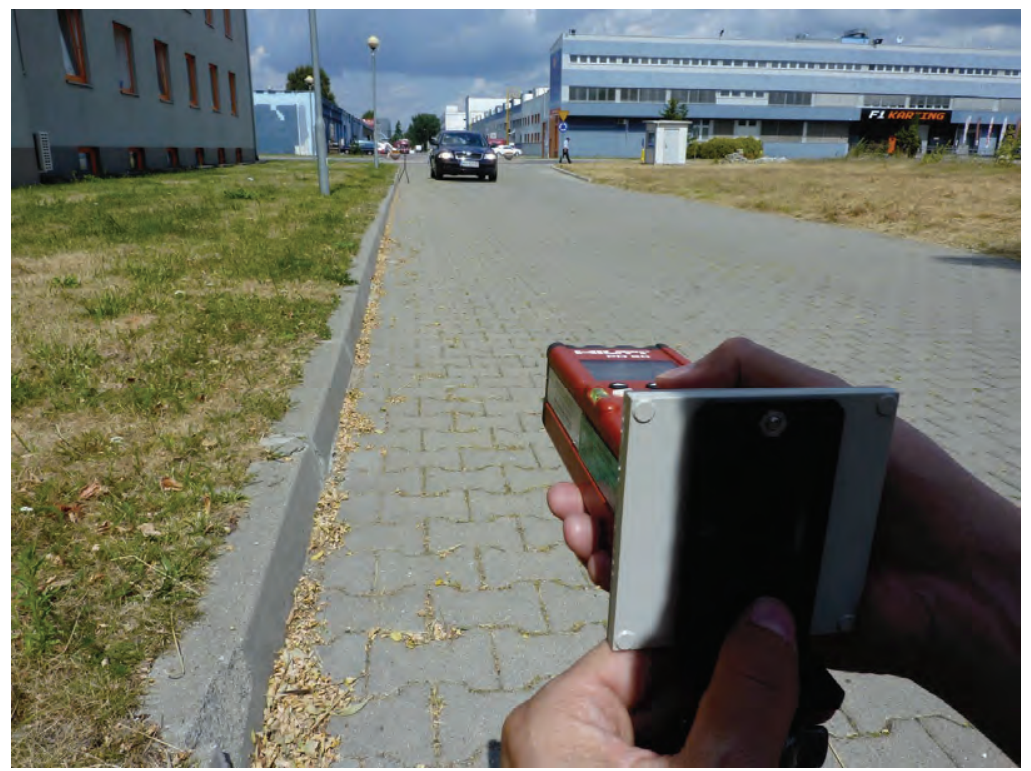

Fig. 2. Measurement of standard distance between photo barriers

On the vehicle doors DATRON optical head was mounted (Fig. 3). Signal from the optical head was recorded with Bruel \& Kjaer type 3560-B analyzer. The standard distance was measured several times. 


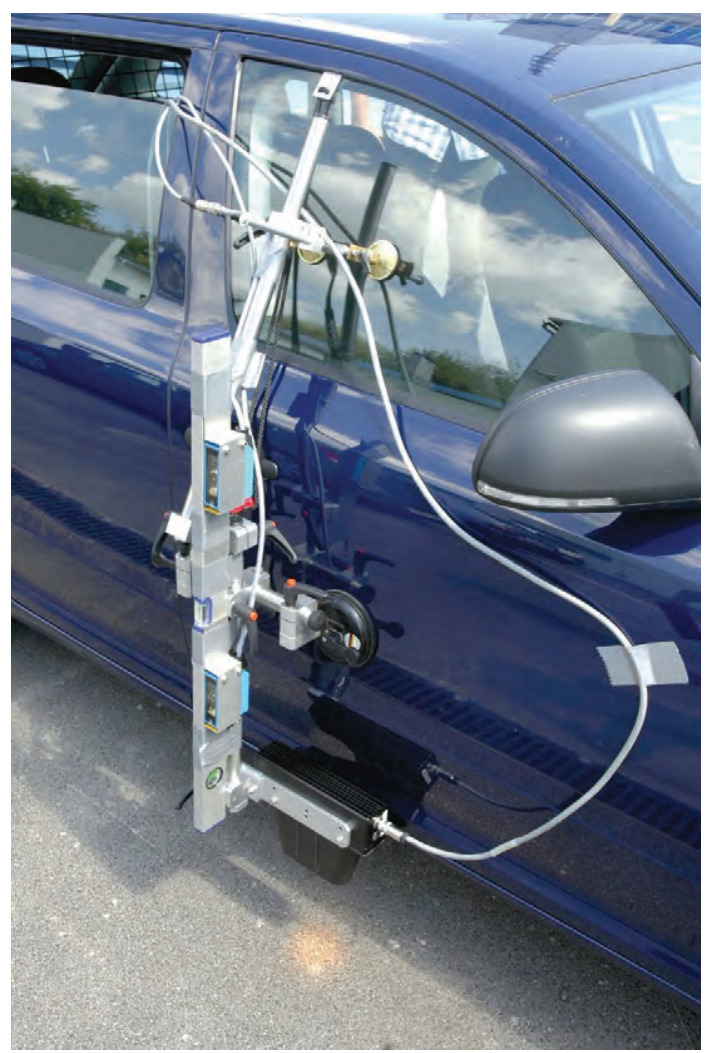

Fig. 3. Optical head mounted to vehicle

\section{Measuring equipment}

Measurement of distance and speed was recorded with the optical head Datron type DLS 1 connected to B\&K type 3560-B analyzer with B\&K PULSE LabShop version 14.1.1. software. On the vehicle body two photo cells were mounted giving the starting and stopping triggers from the retro reflective elements placed on the road on the standardized distance track. The signal coming from the lower photocell was a starting trigger and from the upper one was a stopping trigger. Distance between retro reflective elements was measured with laser distance meter HILTI type PD28.

In distance and speed measurements optical head was used. The changes of the images of the moving road under the optical sensor were analyzed. The measuring object is illuminated by a collimated beam of light from a powerful projector lamp with a large band-width wavelength. The lens system produces an image of the object and focuses this into the plane of a grating. A movement of the sensor or the surface causes a movement of structure points on the grating. From this a modulation is produced on the surface of the two photo receivers. With relative movement of the sensor and measuring surface, the incoming light is split by the grating after depiction and transmitted to the two photo diodes.

The frequency corresponding to the stationary sensor is acquired for a second time with a reference signal transmitter and supplied to the evaluating electronics as a reference and control variable for the motor speed. The true-signed speed is determined from the difference between the measured and reference frequencies [1].

\section{Measurement results}

The length of standard distance track was measured 5 times. 15 measurements were conducted on each surface. In Tab. 1 average value of length measured with laser distance meter (reference value) and optical head including standard deviations results are given. 
Tab. 1. Results of the standard measurement track length [m]

\begin{tabular}{|l|c|c|c|c|c|c|}
\hline \multirow{2}{*}{ Parameter } & \multicolumn{2}{|c|}{ Asphalt surface } & \multicolumn{2}{c|}{ Concrete surface } & \multicolumn{2}{c|}{ Paving BAUMA blocks } \\
\cline { 2 - 7 } & $\begin{array}{c}\text { reference } \\
\text { value }\end{array}$ & $\begin{array}{c}\text { measured } \\
\text { value }\end{array}$ & $\begin{array}{c}\text { reference } \\
\text { value }\end{array}$ & $\begin{array}{c}\text { measured } \\
\text { value }\end{array}$ & $\begin{array}{c}\text { reference } \\
\text { value }\end{array}$ & $\begin{array}{c}\text { measured } \\
\text { value }\end{array}$ \\
\hline average value & 20.10 & 20.152 & 20.10 & 20.156 & 20.10 & 20.160 \\
\hline standard deviation & 0.0012 & 0.021 & 0.0007 & 0.025 & 0.0004 & 0.019 \\
\hline
\end{tabular}

Figure $4(1,3,5)$ presents average values of the measured standard lengths with optical head and $(2,4,6)$ average values of reference lengths measured with laser distance meter. This figure also presents range of values deviation equal \pm 3 standard deviations characterizing precision of measurement. Differences in measured test track length with optical head are within the limits of measurement errors.

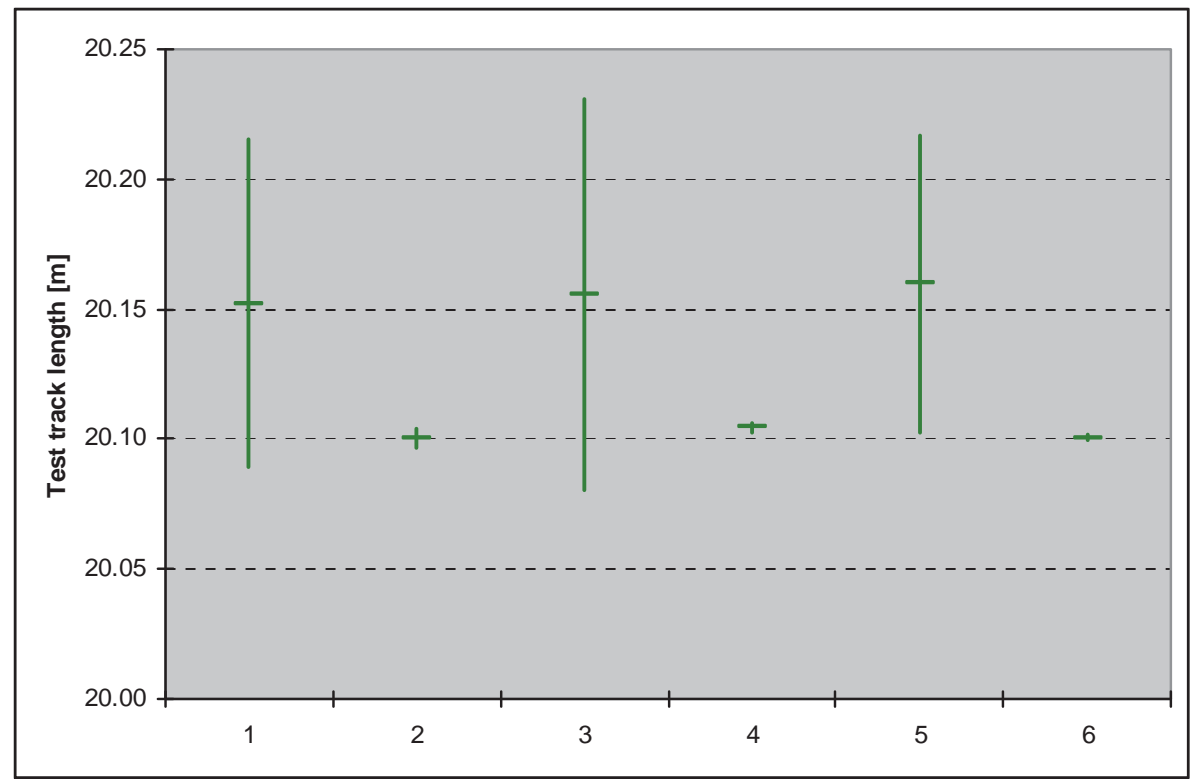

Fig. 4. Length of measured standard test track -average values with standard deviation; 1 - measured asphalt surface, 2 - reference asphalt surface, 3 -measured concrete surface, 4- reference concrete surface, 5 - measured pavement of Bauma bricks, 6 - reference pavement of Bauma bricks

Average value of the test track length measured with optical head for each testing surface is greater from the reference value measured with laser distance meter about $0.056 \mathrm{~m}$ (calculated differences are $0.052 \mathrm{~m} ; 0.056 \mathrm{~m} ; 0.060 \mathrm{~m}$ ). This almost equal difference of measured values suggests that the systematic error has happened. One of the error sources could be the manufacturer's defined calibration coefficient for optical head. Due to the test scope (verification whether remarkable length differences in measurements on different road surfaces are observed) calibration was not performed before tests. Precise measurement of length was used for placing retroreflective elements in the same distance for each test track. The other systematic error could be the method of calculation of reference length value. The procedure for calculation of reference value is: placing retroreflective elements in the approximated distance with these retroreflective elements at a $90^{\circ}$ angle to the test track and performing the length measurements with laser distance meter, turning retroreflective elements with $90^{\circ}$ angle until parallel position to the test track was reached. Due to the construction of the fixing of the retroreflective surface which was in offset to the axis of rotation, the change of the length value measured with laser meter was observed. The source of error could origin from insufficient offset measurement accuracy. 


\section{Conclusions}

The measurements of the test track length with different structure of road surface proved that differences are lower than uncertainty of the measured result for this test method. On the basis of the conducted test it is not possible to conclude that different road surface structure and quality have influence on the distance and speed measurement results. Observed differences for distance measurements are lower than $0.1 \%$ of measured value. Therefore the road surface influence on the measurement result may be ignored.

\section{References}

[1] Operating Manual, DLS 1, Datron-Messtechnik GmbH.

[2] Lewandowski, A., Kędziora, K., Malujda, J., Waluś, K. J., Methodology of measurement of motion parameters of passenger vehicles, Institute of Forensic Research in Cracow, Poznan University of Technology, 2009.

[3] Tanelli, M., Savaresi, S. M., Cantoni, C., Longitudinal vehicle speed estimation for traction and braking control systems, Computer Aided Control System Design, 2006 IEEE International Conference on Control Applications, 2006 IEEE International Symposium on Intelligent Control, 2006 IEEE, pp. 2790-2795, 2006. 
